\title{
Multidimensional Perspective and Making Up the Shortcoming of the Performance Appraisal of Public Sector in China
}

\author{
Yong $\mathrm{Du}^{1} \&$ Jiali $\operatorname{Han}^{1}$ \\ ${ }^{1}$ School of Economics and Management, Southwest University, China \\ Correspondence: Yong Du, School of Economics and Management, Southwest University, Chongqing, China. \\ E-mail: dy772012@126.com
}

Received: November 20, 2013

Accepted: December 11, 2013

Online Published: January 23, 2014

doi: $10.5539 /$ ibr.v7n2p22

URL: http://dx.doi.org/10.5539/ibr.v7n2p22

\begin{abstract}
The performance management of public sector is when the public sector perform its public duty actively, on the basis of the unification of intestine management and exterior benefits, quantity and quality, economic factor and ethic political factor, rigidity criterion and soft criterion, the process to obtain the largest pubic output. The organization review and evaluate the performance of public personnel, such as politics diathesis, representation of operation, behavior of action and harvest of work, then implement rewards and punishment, in order to offer the power of inspiriting the public personnel to improve their behavior, and achieve the goal of increasing the integer efficiency of the public sector finally. Text point out the miss and drawback of performance appraisal of public sector in China, and try to put forward some solutions.
\end{abstract}

Keywords: the public sector, performance appraisal, the performance of public sector, the performance appraisal of public sector

\section{Introduction}

The performance appraisal of public sector is when the public sector perform its public duty actively, on the basis of the unification of intestine management and exterior benefits, quantity and quality, economic factor and ethic political factor, rigidity criterion and soft criterion, the process to obtain the largest pubic output. The organization review and evaluate the performance of public personnel, such as politics diathesis, representation of operation, behavior of action and harvest of work, then implement rewards and punishment, in order to offer the power of inspiriting the public personnel to improve their behavior, and achieve the goal of increasing the integer efficiency of the public sector finally. Modern performance appraisal has brought a huge impact on the traditional bureaucratic government model of the public sector. It should be said that has played a positive role on regulating the work behavior of public personnel and improving public sector efficiency. But we must also recognize that has brought a lot of obstacles because of the lack of public organizations itself, evaluation method and technology.

In theory the performance evaluation of public sector lack scientific and systematic in many aspects, such as conceptual framework, system design, assessment procedures, methods and technical. in practice because of Multiple objectives and inherent conflict, the public sector output is difficult to quantify, evaluation information system is not perfect, Performance evaluation is difficult to determine, Institutions and personnel in their own interests and so on, which constitute a series of unfavorable factors in public sector performance evaluation. Text is on the defects of public sector performance appraisal in our country for multi-dimensional perspective, in order to find concrete measures for making up for the defects.

\section{The Defects in Assessment System}

Current performance evaluation system is fragmented, which don't apply a set of systematic, consistent system of standards, procedures and method in Assessment and evaluation. In the daily management work, although there is some performance appraisal system, enforcement of the system is relatively weak. Most of the appraisal work focuses on the year-end assessment, and fully in accordance with the unified arrangements of the superior, not well combined with the work characteristics and the nature of the work of its own. Incorporate is:

\subsection{Position Classification is Not in Place}

Position classification management system provides an objective basis for human resource assessment, which is 
conducive to implementing the principle of specialization, improving institution-building and setting a quota of staff. IT is the core and soul of appraisal system. However, the position classification in China is still underdeveloped. The job description is not detailed and division of responsibilities is not clear. Which makes the position description not only lost assessment scale value, and also lost the attractiveness of civil servants has become a mere scrap of paper.

\subsection{Assessment Criteria Lack Refinement and Specific}

The assessment criteria are too general often lead to distortion of the assessment results, and it also damage the fairness and effectiveness of evaluation seriously. China currently existing civil service examination system specified in the "morality, diligence, and achievements, to", which is only four standards of the provisions on the principle. This makes examiners at a loss and assessment work difficulty to achieve the ideal effect.

\subsection{Assessment Responsibility System is Not Perfect}

"Civil Servant Law" made general requirements on state responsibility subject of examination. But it does not specify the examination subject what kind of responsibility they should bear in each link of assessment, what awards they can receive by fulfilling the responsibility earnestly, and what if their mistakes. So in the examination practice, the main responsibilities of the civil service examination are not clear, and also their mistakes cannot be.

\subsection{Assessment System is Single}

The current examination system only pays attention to the annual assessment, neglect the daily assessment. This leads annual assessment exam without basis, and assessment results are not comprehensive, inaccurate, untrue, lack of authority. In the qualitative and quantitative assessment it only pay attention to qualitative appraisal, ignore the quantitative evaluation. So the civil service examination standard is not specific and science. In the civil service examination process, some units and departments don't want to spend too much energy to study and develop scientific appraisal index system. But by racquet head, they set a few casually, which are just stayed on the basis of qualitative and lack operability. Just let the leadership assessment subordinate civil servant, not for junior civil servants for the democratic appraisal to the leader. This is neither fair nor reasonable. Principles of democracy and openness cannot be implemented and role of subordinate staff and the masses is ignored.

\subsection{Enforcement of Appraisal System is Not Enough}

Due to the lack of understanding from the height of strategic performance assessment, performance appraisal is despised in the daily management. The basic framework of the performance evaluation system lack specific content and maneuverability, which seriously affects the enforcement of the performance appraisal system.

\section{Defects in the Assessment Process}

\subsection{Evaluation of Subjective Color is Thick and the Uplink to Assess is Failure}

Most of our country's administrative management carrying out responsibility system of administrative leader, it's easy to cause individual arbitrariness.

\subsection{The Lack of Fair in Appraisal Process}

A lot of public sector performance evaluation in our country in order to take into account the interests of every member, take simple proportional distribution quota or rotation of egalitarianism form to select outstanding employees. It is obviously unfair.

\subsection{The Lack of External Supervision}

In the assessment of civil servants, direct supervisor evaluating subordinates tend to have larger evaluation weight coefficient, but ignored the public appraisal and examination of civil servants. This can't really reflect the meaning of incentive and constraint of civil servants. So public servants shall be subject to the supervision of the public become meaningless.

\subsection{The Assessment Results are Prone to Failure}

The results of the assessment should be the basis of a civil servant's management activities, such as rewards and punishments, lift. In practice, however, there are some obvious problems: more related factors of civil service pay system of civil service pay system is often outside the system, but as the factor of system performance evaluation has been swallowed up by the "hidden rules". So the assessment results are failure.

\subsection{The Existence of "Confidential” Doctrine}

The traditional performance's evaluation is usually taken for granted as "secret". Personnel assessment is not 
public increasing people's appraisal of unease and distrust of the personnel department for examination and assessment of the "secret" doctrine also interfere with the employee should play a role of guiding education.

\subsection{Performance Evaluation and Development Strategy Does Not Adapt}

Performance appraisal is not an end in itself but a means, which is focusing on how to implement the strategic set of institutional arrangements. Its final purpose is not only to provide the appropriate basis for how to split the "cake", but for the "cake" bigger. If the performance appraisal system is not designed for their strategic objectives, but merely confined to the employee's job performance, then this form of performance appraisal and the result is not too big significance.

\section{The Defects of Assessment Method}

\subsection{Method is Simple and Strong Subjectivity}

Qualitative assessment is traditional human resources assessment method in our country. This assessment is often affected by the personal feeling, impression and experience. It not only lack objective criteria, but also subjective and optional sex is big, which make it to understand from the dynamic and easy distortion of assessment results, such as "the error of halo effect", "the recency effect error", "the effect of error" and so on.

\subsection{The Grades of the Assessment is Less, Difficult to Pull the Grade}

Assessment such settings is an important content of assessment index system, the more, the higher the degree of differentiation, the more conducive to the inspection accuracy. In the public sector examination, if the results of the appraisal grade are less, it will lead ability and performance of excellent and poor employees enjoy the same treatment, almost no difference in the same level, which greatly weakened the incentive function of the evaluation system.

\subsection{Assessment of Backward Technology and Lack of Scientific}

The inspection department with the backward technology and method of performance appraisal performance restrict the scientific performance appraisal. Just as some scholars have pointed out, China's public sector performance evaluation is still at the level of the original on the handicraft industry. Evaluation system is spontaneous, blind random, one-way, passive and closed and mysterious. For the assessment method, mainly take the traditional "Germany, can, diligent, accomplishment, low-cost" assessment method. Assessment index of the method under the guidance is abstract, vague, difficult to quantify. More important is no reasonable set of evaluation target value and reward standard.

\section{Dilemma of Public Organization Under the Characteristics of Performance Appraisal}

\subsection{The Output of Public Sector without Non Market is Difficult to Quantify}

The product or service of the government departments is usually some non commodity outputs. They enter the market trading system, but it is very difficult to form a reflecting the production cost money prices which result the difficulty technical in accurate measurement. Public goods or services provided by governments are more monopoly. This also is not so easy to through the horizontal comparison to measure the performance of the government departments. Performance evaluation index is difficult to quantify. And it has long been a difficult problem of the civil servant performance management in China.

\subsection{Diversity and Internal Conflict in Public Sector Target}

The ultimate goal of the government organization is often decided to achieve the optimization of the public interest. So what is the public interest, different levels, different departments of the government organization to reflect what is in the public interest, what is the difference, whether to have inner conflict. They themselves are difficult to theoretically clarify the problem thoroughly.

\subsection{Effect of Public Department and Staff of Their Own Interests}

Public choice theory representative Buchanan said, the starting point of individual behavior in the economic field is "self-interest", the political arena too. The government is also self-interest motivation, truly selfless ACTS just special case, not universal. Politicians and bureaucrats always more favor those most able to reflect the interests of their bill. The theory is also applicable to the public sector performance evaluation.

China's public sector managers in the way of performance management is still a long way to go, not only to have a correct understanding and determination, but also to take across the various traps and implement scientific performance management. 


\section{Some Ways to Compensate for the Public Sector Performance Evaluation Defects}

\subsection{Try to Make Clear, Specific Performance Objectives}

The public sector should make target as possible clear, specific, detailed in terms of performance improvement. The target expression should be clear, easy to understand; the target expression should be specific, rather than general; objectives shall be measurable, not difficult to measure; goal should be result oriented, rather than process oriented. At the same time, the public sector should as far as possible to eliminate conflicts between multiple objectives, in order to seek the balance between performance and demand, justice, democracy and other factors.

\subsection{Adjust Measures to Local Conditions to Design the Performance Indicator System}

According to the concrete manifestation of the way the public sector performance, designed to measure various public sector performance effective specific performance indicators system. For public sector quantifiable output should design quantitative index system, and it is difficult to quantify the output will follow the following principle to design index: specific, clear, measurable, on target and evaluation; Can be achieved; the reality, not the imaginary and has the time limit. At the same time in the design performance indicators also must have a good grasp of the following combination pairs: (1) The combination of internal and external indices; (2) Combination of quantity index and quality index; (3) Combination of positive indicators or negative indicators; (4) Combination of Technical indicators and democracy index; (5) The combination of objective indicators and subjective indicators; (6) Points out that the indicators combined with return indicators; (7) Performance measures combined with performance indicators; (8) The administrative cost index combined with business cost index; (9) The combination of individual and group indicators. Due to the objectives of the organization change frequently, so the performance index system should have a certain degree of flexibility and elasticity, and continue to accept the review and modify.

\subsection{To Strengthen the Construction of Performance Management of Institutionalization and Legalization}

In order to guarantee the performance management reform to further development, so as not to cancel or stop, we must take the performance management reform into the institutionalization and legalization, so as to ensure the continuity and the continuity of the reform.

1) In the form of legislation to establish the status of performance management can guarantee the basic link of performance management into public sector management, so as to encourage public sector efforts to improve performance.

2) Establish the authority of the performance evaluation in law, and establish the independent status of the performance evaluation mechanism. Independent agency of the government performance evaluation, and released to the public evaluation results.

3) Establish system and the specification of performance management, and make detailed regulations on the whole process (formulate vision, mission and objectives of the organization; performance planning; plan; performance; performance evaluation) of performance management, which will make performance management law and rule-based.

\subsection{The Establishment of Democratic Participation Mechanism}

The successful performance management requires the joint efforts of the whole organization and volunteer, which requires the formation of middle managers and staff to the required activities to achieve results initiatives will support, or at least not against, and get them involved in the formulation and implementation of the performance management process. In the public sector, if an effort to improve their performance lack active participation of the entire staff, it means that the reform will face greater difficulties, are more likely to be delayed.

Since the essence of public sector is to serve the public, then the final right of government performance evaluation should depend on the public. Therefore, to improve public sector performance must achieve a fair attention and participation, achieved recognition and support of the public. Otherwise, the government performance management reform is lack of legitimacy and effectiveness. The public sector must remain with the public full, timely and effective communication.

\subsection{Development and Optimization of Organizational Capabilities}

The effective implementation of the performance management "requirements development strategic planning, operation plan, performance measurement and the ability to project evaluation; innovation and the ability of the test and research on best practices, and implementing performance information using the ability of the 
management method of". Therefore we need to reform the organization, so that the organization form based on the performance of the corresponding ability:

1) The introduction of a large number of performance management experts or talent.

2) To strengthen the training of organization managers or staff.

3) Giving authorization and incentive to make government workers devote themselves into the work.

4) Transformating organizational culture to form organization culture based on the performance.

5) The establishment of electronic government can make the government organizations tend to flat. It also can make transfer, communication, feedback information more quickly, and improve the efficiency and quality of the operation of the government. This can provide convenience for citizens' extensive participation, enhance the interaction between government and citizens.

\subsection{To Be Able to Continue to Find Problems and Improve the Performance of the Opportunity}

To improve and optimize the work of the government performance evaluation is an ongoing process. Government agencies should analysis or evaluate the performance data once a quarter or more frequent. Through developing the right measurement of the performance to find the problems existing in the performance management, and look for opportunities to improve it. When carrying out performance evaluation, it shall have the branch institutions of the internal and external key stakeholders to participate in. And it is very important to improve performance to listen to their comments.

\subsection{Establish and Perfect the Performance Management Information System}

Information is the foundation of performance management, therefore we must construct the effective government activity and the will of the public information feedback channels and means, in order to guarantee the information in different levels and between different systems fast smooth flow and retrieval. Now we should make full use of information technology, to realize the modernization of information management, and improve the speed and quality of information collection, processing. At the same time, it is very important to improve the government performance by creating information transparency and keeping good communication and effective interaction between the public sector and civil society.

Improving the government's public sector performance is one of the goals of public management. Practice shows that the performance management reform in western developed countries plays a very important role to improve and enhance the performance of the government. Performance management to exert its function must be in combination with other reform measures, forming a system of "force". These institutional arrangements mainly includes: decentralization, responsibility mechanism, citizens' direction, result oriented, competitive mechanism and incentive mechanism, and e-government.

\subsection{Draw Lessons from Foreign Civil Service Examination System}

1) Combination of qualitative and quantitative evaluation. Quantitative assessment, as a result of assessment standard specific, objective, unity, minimizes the assessment of subjective arbitrariness and one-sided. Combination of qualitative and quantitative evaluation, is given priority to with qualitative evaluation, quantitative and qualitative assessment is required to organically, the judgement of civil servant's annual appraisal based on the analysis of the quantitative evaluation, namely, embarks from the qualitative assessment, with reference to the measurement data, a comprehensive evaluation, finally determine the overall qualitative evaluation conclusion.

2) Year-end combined with usually regular inspection. Is given priority to with normal examination, usually inspects the main assessment of civil servants on duty in the political attitudes, thoughts and situations to perform the job, achievements and mistakes. Routinely held irregularly, according to the actual needs, a month, a quarter, or complete a task, all can be carried out. The year-end assessment combined with regular check at ordinary times, reflects the unity of the assessment work continuity and stage.

3) Combined assessment of leadership and the masses, giving priority to with assessment of leadership. Leadership assessment, refers to the subordinate level examination by the administrative leadership at all levels, implement the responsibility system of chief. Mass appraisal, refers to organized the masses to participate in the examination. The officer in charge of assessment system need strengthen the democratic supervision. The assessment should accept the parent organization of the inspection and guidance, to set up the agencies with delegates civil service examination, collective examination and the inspection gradation, to evaluate feedback assessment results, the assessment object has the right to request for reconsideration, complaint. 
To do so: (1) will make objective and fair evaluation of civil servants, motivation and spur civil servants work hard, strive for first-class civil servant performance appraisal. Civil service examination, in order to improve the work performance can get social recognition and respect, so as to satisfy the civil servant's pursuit of honor, to improve the enthusiasm of civil servants; According to the assessment results, determine the rewards and punishments, lift and salary of civil servants, so as to encourage advanced, lash junior role; The civil service examination can also encourage civil servants conscientious, hard work, efforts to create first-class performance. (2) is helpful to civil servants, strict management and strict supervision in the process of examination, the inspection authority will assess the various matters, let the masses to participate in the review, is also the course of the democracy to exercise strict supervision over the civil servants; (3) is helpful to improve the management of civil servant system of civil servants is by civil servants position classification, post appointment, evaluation, training, communication, management content such as avoidance, salary welfare, resign fired form a complete system. (4) to strengthen the authority of the cultivation of clean government civil servants, to master a certain power, due to the influence of the social bad style and the level of moral, limit, the possibility of rights have been abused.

\section{Results}

Civil servant performance appraisal in our country should stick to the principle of combining quantitative and qualitative assessment index, in specific operations, for work really hard to quantify, generally take good, good, general and poor class to assess, and then gives each grade of fixed points. Assessment of using modern means of government departments can according to their own assessment criteria and evaluation purpose, choose different modern performance evaluation methods, such as the written evaluation report, the critical incident method, the chart type grade assessment, alternating sorting method, paired comparison method, the scale for assessment of target evaluation, behavior orientation, etc., in order to improve the efficiency of civil servant performance appraisal. Ensure continued performance of the communication performance of civil servant's performance management communication throughout the whole process of the performance management, the implementation of performance planning, performance planning, performance appraisal, performance feedback and performance results, the use of all need to keep good performance communication and civil servants in our country should adopt flexible and effective means of communication to strengthen communication, ensure the smooth communication channel and the civil servant's performance appraisal more scientific.

In addition also need to point out that, in order to ensure the smooth implementation of perform In addition also need to point out that, in order to ensure the smooth implementation of performance appraisal, also note the following questions: first, to secure the support of top leaders. And I will be have a defense of evaluation too degrees, implementation of the new evaluation method is more vulnerable to many doubts and resistance, gain support from senior leadership, the implementation of the top-down, will be conducive to the implementation of process smoothly. Second, to make a good information communication within the authority in advance, make all participate in the inspection staff recognition of the importance of performance evaluation and superiority, build mutual trust. Third, in the process of implementation, as far as possible make all joined in the work of the evaluation personnel involved. Participation and more help to jointly promote the evaluation, the result feedback and achieve organizational goals. Fourth, shall ensure that the reviewers in the implementation of anonymity, to eliminate (mainly colleagues and subordinates), ensure that the results of objective and true.

\section{Acknowledgements}

The authors are grateful for financial support from the fund of Central University basic research funds in Southwest University (SWU130911, SWU1309202).

\section{References}

Can, H. L. (2007). The government employee system. The Knowledge Economy, (8).

Fa, G. X. (2004). National civil service system (pp. 105-118). Hangzhou: Zhejiang university press.

Jian, R. H.(2005). New public management. Beijing: Social sciences academic press.

Jiang, W., \& Ye, Y. H. (2003). Public sector human resource management. Beijing: the central committee of the communist party of China party school press.

Ling, Q. C. (2004). Performance management. Beijing: China textile publishing house.

Wen, G. L. (2006). The public sector human resources development and management. Beijing: Social sciences academic press.

Xian, G. Y., \& Xiao, W. C. (2004). Public sector human resource management. Science press. 
Yue, Z. (2004). Public sector performance management. Fuzhou: Fujian people's publishing house.

Zhi, G. C., Dong, G. S., \& Ling, W. (2008). Introduction to China's public sector human resource performance appraisal method of the model created. Journal of knowledge economy, 2, 36.

\section{Copyrights}

Copyright for this article is retained by the author(s), with first publication rights granted to the journal.

This is an open-access article distributed under the terms and conditions of the Creative Commons Attribution license (http://creativecommons.org/licenses/by/3.0/). 